\title{
Developing a Broadband Adoption Model in the UK Context
}

\author{
Yogesh K. Dwivedi ${ }^{1}$, Navonil Mustafee ${ }^{1}$, Michael D. Williams ${ }^{1}$, and Banita Lal ${ }^{2}$ \\ ${ }^{1}$ School of Business \& Economics, \\ Swansea University, \\ Swansea, United Kingdom \\ ${ }^{2}$ Nottingham Business School, \\ Nottingham Trent University, \\ Nottingham, United Kingdom
}

\begin{abstract}
This research examines the factors affecting the consumer adoption of broadband in the United Kingdom. A conceptual model of broadband adoption was developed by selecting and justifying a number of relevant constructs from the technology adoption literature. The model was then empirically tested by employing survey data that was randomly collected from 358 UK broadband consumers. The findings suggest that, with the exception of one construct that was included in the conceptual model (namely, knowledge), all of the constructs significantly influence consumers when adopting broadband in a UK household. The significant constructs include relative advantage, utilitarian outcomes, hedonic outcomes, primary influence, facilitating conditions resources, and selfefficacy. Furthermore, when considering the behavioral intention and facilitating conditions resources constructs together, they significantly explain UK broad band adoption behavior. The theoretical contribution of this research is that it determines and integrates the appropriate constructs from the technology adoption literature in order to enhance the knowledge of technology adoption from the consumer's perspective. This research has implications for policy makers and broadband providers since the results of this study can be exploited by the aforementioned stakeholders in order to encourage and promote the adoption and usage of broadband among the general population.
\end{abstract}

Keywords: Broadband, adoption, consumer, TPB, DTPB, UK.

\section{Introduction}

Broadband offers several advantages to the public and to private sector organizations in terms of cost savings, efficiency, and competitiveness at a macro level (Oh et al. 2003; Sawyer et al. 2003). Broadband diffusion is regarded as a measure of international competitiveness (BSG 2004; Langdale 1997; Oh et al. 2003; Sawyer et al. 2003) and governments around the world have set ambitious targets for the deployment of broadband services (National Broadband Task Force 2001; Office of the e-Envoy 2001; Office of Technology Policy 2002). This is because a high 
penetration rate of broadband is perceived to have a positive impact on the growth and development of the Internet, electronic commerce, and the information economy (Lee et al. 2003; Sawyer et al. 2003).

Broadband technologies can also improve the quality of life in various ways. For example, they facilitate home working/telecommuting (Suomi and Pekkola 1998), thereby contributing to flexibility of life style for individuals, permitting space savings for organizations, and helping to decrease carbon footprints by reducing travel between home and the workplace. Similarly, broadband is essential to implement telemedicine-enabled health service delivery, particularly for older people and for dispersed populations located in remote areas. Yet another important use of the technology is support for e-Learning and distance learning. e-Learning both complements face-to-face classroom education with computer-aided teaching (so called blended learning), and enables those who are unable to attend a formal educational environment (e.g., people in remote areas) to learn and gain knowledge by accessing online resources through an Internet connection (distance learning). Many governments have realized the potential of broadband technologies and have made available an increasing number of government services for citizens to access online. Broadband can be utilized by household consumers/users in various other ways and the reader is referred to Dwivedi et al. (2006a) for further examples.

Governments in a number of countries, including South Korea, Japan, Hong Kong, Sweden, Australia, Canada, the United Kingdom, and the United States, have made large investments for developing a broadband infrastructure that will deliver highspeed Internet access to end users, including household consumers and small and medium enterprises (BSG 2004; OECD 2001; Oh et al. 2003; Sawyer et al. 2003). In recent times, some of these broadband pioneers have rejuvenated their efforts to provide broadband access to all citizens. For example, the USA has formulated the National Broadband Plan that "shall seek to ensure that all people of the United States have access to broadband capability." "Similarly, the prime minister of Australia has announced plans to build a new national broadband network that will aim to reach 90 percent of Australian households at a cost of $\$ 30$ billion (Radio Australia News ${ }^{2}$ ). Such initiatives indicate that the development, deployment, and diffusion of broadband infrastructure and technologies requires continued and long-term planning and strategic thinking.

Although broadband offers several benefits for both individual consumers and businesses (some of these benefits being mentioned earlier), in many countries its demand has not increased in line with expectation. Previous studies have argued that the provision of broadband is more "demand constrained" than "supply constrained" (Crabtree 2003; Oh et al. 2003; Stanton 2004). Thus it may be argued that in order to enhance the widespread adoption and use of broadband, it is essential to focus on understanding the factors influencing the decisions of household consumers. Previous research undertaken on the adoption of technology (e.g., adoption of personal computers by residential consumers) has also emphasized the role of the demand perspective (see, for instance, Venkatesh and Brown 2001). Similarly, initial studies on consumer adoption of broadband have also argued the issue of demand constraint,

\footnotetext{
${ }^{1}$ http://www.broadband.gov

${ }^{2}$ http://www.radioaustralianews.net.au/stories/200904/2538028.htm
} 
and these studies have attempted to study consumer attitude and behavior toward broadband adoption. Some of these studies are briefly described here. An initial study by $\mathrm{Oh}$ et al. (2003) examined individual-level factors affecting the adoption of broadband access in South Korea by combining factors taken from Rogers' (1995) diffusion theory and the technology acceptance model (Davis 1989; Davis et al. 1989). The findings of this study suggest that congruent experiences and opportunities in adopting a new technology affect user attitudes through the three extended technology acceptance model constructs; namely, perceived usefulness, perceived ease of use, and perceived resources (Oh et al. 2003). Stanton (2004) analyzed the secondary data pertaining to U.S. broadband consumers with the objective of studying the digital divide. This study highlighted an urgent need to better understand the demography and other factors of broadband adopters and non-adopters in order to increase the growth rate of broadband and to bridge the digital divide. The research presented in this paper forms a part of a larger project; some of the findings having already been published (see Choudrie and Dwivedi 2005, 2006, 2007; Dwivedi and Irani 2009; Dwivedi et al. 2006a; Irani et al. 2009). However, the initial studies resulting from this project had several limitations; they either adopted a parsimonious theoretical framework to analyze and interpret the data (Irani et al. 2009) or they were of an overly descriptive nature (Dwivedi and Irani 2009). With the objective of overcoming these limitations, this paper adopts a broad theoretical framework by integrating constructs (see section two) from dominant theories and models and then utilizes statistical techniques including factor analysis, regression analysis, and logistic regression analysis to measure the influence of independent variables on dependent variables.

Bearing the aforementioned discussion in mind, the aim of this study is to investigate factors affecting the consumer adoption of broadband in the UK context. The aim has been achieved by developing a conceptual model by identifying and integrating constructs from extant literature on IT/IS adoption and validating/testing it by utilizing empirical data. The remainder of the paper is structured as follows. The next section briefly describes the proposed conceptual model. Section three discusses the research methodology. The findings are presented in section four while the conclusions and implications of the work are discussed in section five.

\section{A Conceptual Model of Broadband Adoption}

Our proposed conceptual model of broadband adoption (Figure 1) is based on the underlying principle of the decomposed theory of planned behavior (DTPB) and utilizes constructs from the model of adoption of technology in households (MATCH) and diffusion of innovation (DoI) theory. In keeping with the works of Ajzen (1991), Rogers (1995), Taylor and Todd (1995), and Venkatesh and Brown (2001) among others, our proposed adoption model postulates that behavioral intentions (BI) to adopt broadband are determined by the following three forms of construct: (1) attitudinal constructs (relative advantage, utilitarian outcomes, and hedonic outcomes) that represent consumers' favorable or unfavorable evaluation of the 
behavior in question (in this case, adoption of broadband); (2) normative constructs (primary influence and secondary influence) that represent perceived social pressure to perform the behavior in question (i.e., adoption of broadband); (3) control constructs (knowledge, self-efficacy, and facilitating conditions resources) that represent perceived control over personal or external factors that may facilitate or constrain behavioral performance. The predictor variables from the aforementioned three categories are expected to determine and explain the BI to adopt broadband, which in turn is expected to predict actual broadband adoption behavior (BAB). The proposed model also includes two independent constructs, namely service quality and secondary influence, that examine sustained adoption of broadband. Figure 1 illustrates the relationship between independent and dependent constructs (readers should note that word limits preclude the description and justification of each individual construct).

\section{Research Methodology}

The survey research method, employing self-administered questionnaires, is considered an appropriate method to examine the adoption of broadband. The empirical data for this study was randomly collected from citizens of the UK by utilizing "UK-Info Disk V11" as a sampling frame. The structure of the sampling frame necessitated the adoption of the stratified random sampling approach for selection of respondents.

Development of the survey instrument comprised three stages: exploratory survey, content validity testing, and instrument testing. The development and validation of the survey instrument, together with a full discussion of the results of the three aforementioned stages, is reported in Dwivedi et al. (2006b). The final questionnaire used in this research consisted of 17 questions. These questions were divided into two categories: (1) multiple-choice questions addressing socio-economic characteristics such as age, gender, education, occupation and income, and type of Internet connections the respondents had access to at home, and (2) seven-point Likert scale questions addressing issues relating to the attitudinal, normative and control factors of broadband adoption. See Dwivedi et al. (2006b) for the list of constructs and corresponding Likert scale items utilized in this study.

Being mindful of the statistical analysis plan, it was decided that the total sample size should be large enough to obtain a minimum of 300 responses. A sample size of 1,500 was estimated to achieve 300 responses. To compensate for any shortfalls in the 300 responses that may occur due to undelivered and partially completed responses, the sample size was duly increased from 1,500 to 1,600 . Thus, a total sample size of 1,600 was considered for this study. In the period between January 2005 and March 2005, a questionnaire pack consisting of a cover letter, a copy of the survey instrument, and a self-addressed prepaid return envelope was posted to a total of 1,600 household consumers in the UK. 


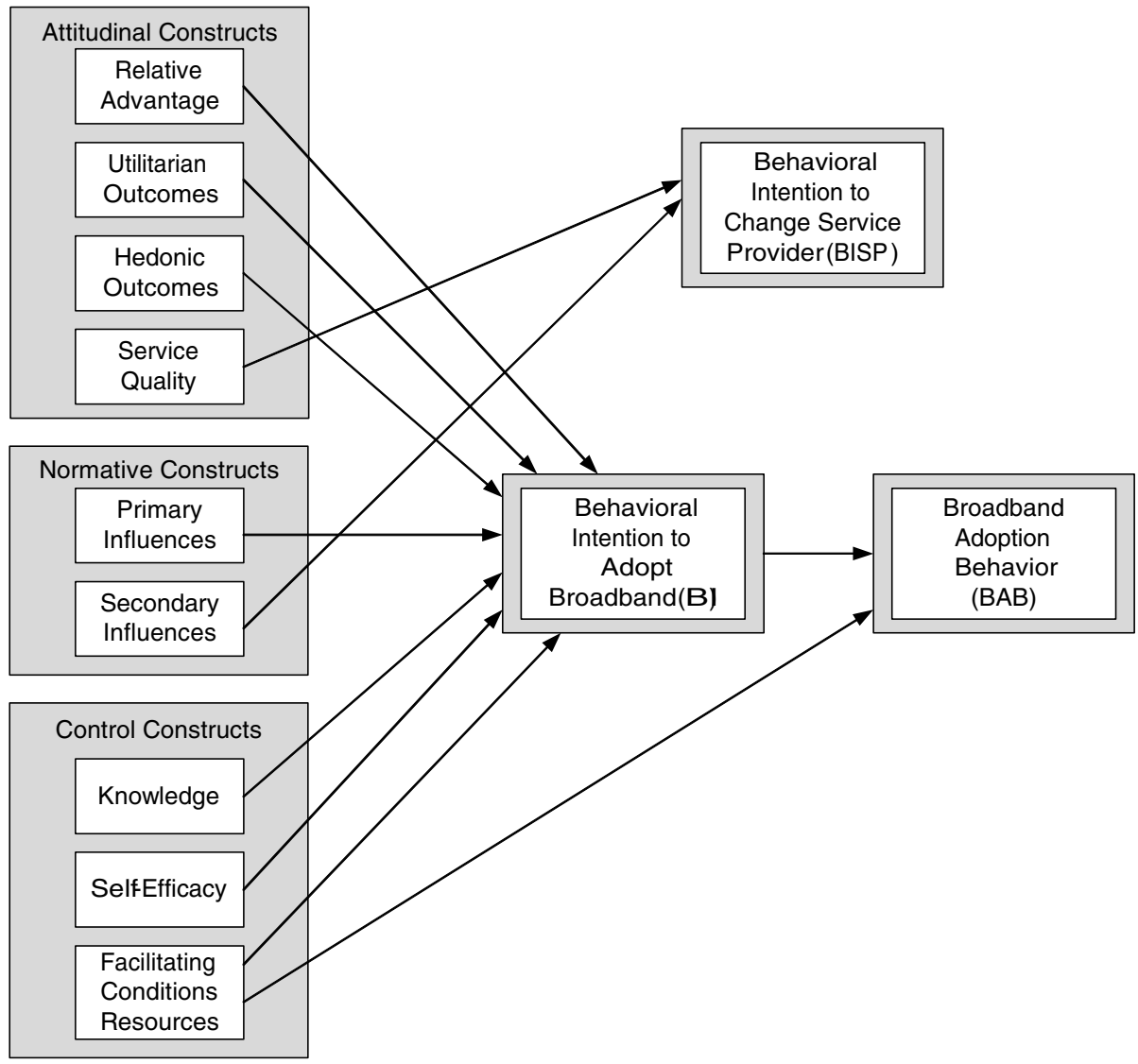

Fig. 1. Conceptual Model of Broadband Adoption (MBA) (Adapted from Ajzen 1991, Rogers 1995, Taylor and Todd 1995, and Venkatesh and Brown 2001)

Table 1. $t$-Test to Examine Non-Response Bias

\begin{tabular}{|l|c|c|c|}
\hline \multicolumn{1}{|c|}{ Variables } & t & df & p \\
\hline Age & .766 & 355 & .444 \\
\hline Gender & .557 & 353 & .578 \\
\hline Internet access at home & .646 & 356 & .519 \\
\hline Type of connection & -1.609 & 306 & .109 \\
\hline
\end{tabular}

From the total of 1,600 questionnaires distributed, 300 replies were received within the specified period (January 2005 to March 2005). Of these, 280 questionnaires were usable with the remaining 20 being incomplete, providing a response rate of 17.5 percent. In order to test the non-response bias (Fowler 2002), an additional 200 questionnaires were sent to randomly selected non-respondents from the original 
sample in mid-March 2005. Of these, 40 replies were received, 38 of which were usable with two being partially completed. Findings obtained from the non-response bias test are illustrated in Table 1. Data presented in Table 1 reveals that there were no significant differences in the number of demographic variables between the original respondents and a sample of non-respondents. Responses received from nonrespondents were added to the original responses. It should be further noted that since no substantial changes were made to the final questionnaire after the pilot, it was decided to include pilot responses in the main study. This approach has been followed by other studies (for example, Fowler 2002). Thus, the total number of responses included in the final analysis was 358 .

The data collected was subjected to the following statistical tests. Factor analysis and reliability tests were employed to examine construct validity and internal consistency of the survey instrument. In order to explain the relationship between independent and dependent variables, linear regression analysis and logistic regression analysis were utilized. Logistic regression analysis was also employed in this work to explain the relationship between aggregate measure of independent variables (i.e., behavioral intention and facilitating conditions resources) and the categorical dependent variable (i.e., broadband adoption).

\section{Research Findings}

\subsection{Respondents' Profile}

A profile of the survey respondents is presented in Table 2. Of the 358 responses, 26.1 percent of respondents belonged to the 25 to 34 years age group which formed the largest response category. The category with the least number of responses was the 65 years and above age group with 3.9 percent. In terms of gender, the break was 51 percent males and 49 percent females. The majority of respondents possessed educational qualifications, with 34.6 percent having gained an undergraduate degree and 29.3 percent educated to postgraduate level. The educational category with the least number of responses was the GNVQ/diploma group, with an 8.8 percent response rate. Of the 358 respondents, 308 ( 86 percent) had Internet access at home, the remaining 50 (14 percent) respondents did not have any Internet connectivity. Of the 308 respondents who possessed Internet access at home, 101 (32.8 percent) had a narrowband connection and the remaining 207 (67.2 percent) respondents had a broadband connection.

\subsection{Reliability of the Measurement}

Before presenting the findings, the research instrument was tested for reliability and construct validity. Table 3 illustrates the Cronbach's coefficient alpha values that were obtained to examine internal consistency. Cronbach's $\alpha$ varied between 0.91 for the utilitarian construct and 0.79 for the two constructs hedonic outcomes and service quality. Following Hinton et al.'s (2004) suggestion for cut-off points for reliability, it can be seen from Table 3 that of the seven constructs, two possess excellent 
Table 2. Profile of Survey Participants

\begin{tabular}{|c|c|c|c|}
\hline Variable Category & Percent & Variable Category & Percent \\
\hline \multicolumn{2}{|l|}{ Age } & \multicolumn{2}{|c|}{ Occupation* } \\
\hline$<24$ & 21.0 & A & 10.6 \\
\hline $25-34$ & 26.1 & $\mathrm{~B}$ & 27.4 \\
\hline $35-44$ & 21.6 & $\mathrm{C} 1$ & 19.0 \\
\hline $45-54$ & 19.0 & $\mathrm{C} 2$ & 2.0 \\
\hline $55-64$ & 8.4 & $\mathrm{D}$ & 1.7 \\
\hline$>65$ & 3.9 & Others & 41.0 \\
\hline \multicolumn{2}{|l|}{ Gender } & \multicolumn{2}{|c|}{ Annual Income } \\
\hline Male & 50.6 & $<10 \mathrm{~K}$ & 9.2 \\
\hline Female & 48.6 & $10-19 \mathrm{~K}$ & 16.8 \\
\hline \multicolumn{2}{|l|}{ Education } & $20-29 \mathrm{~K}$ & 17.3 \\
\hline GCSC (O Level/High School) & 11.2 & $30-39 \mathrm{~K}$ & 16.8 \\
\hline GNQV & 8.4 & $40-49 \mathrm{~K}$ & 10.6 \\
\hline A Level (10+2/Intermediate) & 14.8 & $50-59 \mathrm{~K}$ & 7.0 \\
\hline Degree (B.Sc./BA) & 33.0 & $60-69 \mathrm{~K}$ & 9.2 \\
\hline PG (M.Sc./MA/Ph.D.) & 27.9 & $\geq 70 \mathrm{~K}$ & 10.1 \\
\hline \multicolumn{2}{|c|}{ Internet Access at Home } & \multicolumn{2}{|c|}{ Type of connection at Home } \\
\hline Yes & 86.0 & Narrowband & 28.2 \\
\hline No & 14.0 & Broadband & 57.8 \\
\hline
\end{tabular}

*Mainstream professionals such as doctors, lawyers, and judges with responsibility for 25 or more staff members belonged to social class "A," with the same occupations with responsibility for fewer than 25 staff, along with academics, being grouped into social class "B." Skilled, non-manual workers were categorized as social class "C1" and social class "C2," with unskilled manual workers belonging to social class "D." Respondents from the "other" category were unemployed and students.

Table 3. Reliability of Measurements

\begin{tabular}{|l|c|c|c|l|}
\hline \multicolumn{1}{|c|}{ Constructs } & N & $\begin{array}{c}\text { Number } \\
\text { of Items }\end{array}$ & $\begin{array}{c}\text { Cronbach's } \\
\text { Alpha ( } \boldsymbol{\alpha})\end{array}$ & \multicolumn{1}{c|}{ Type } \\
\hline Behavioral Intention (BI) & 358 & 2 & .8790 & High Reliability \\
\hline BISP & 308 & 1 & - & - \\
\hline Relative Advantage (RA) & 358 & 4 & .8481 & High Reliability \\
\hline Utilitarian Outcomes (UO) & 358 & 10 & .9131 & Excellent Reliability \\
\hline Hedonic Outcomes (HO) & 358 & 4 & .7968 & High Reliability \\
\hline Service Quality (SQ) & 308 & 4 & .7912 & High Reliability \\
\hline Primary Influence (PI) & 358 & 3 & .8420 & High Reliability \\
\hline Secondary Influence (SI) & 358 & 2 & .9034 & Excellent Reliability \\
\hline $\begin{array}{l}\text { Facilitating Conditions } \\
\text { Resources (FCR) }\end{array}$ & 358 & 4 & .8114 & High Reliability \\
\hline Knowledge (K) & 358 & 3 & .8193 & High Reliability \\
\hline Self-efficacy (SE) & 358 & 3 & .9026 & Excellent Reliability \\
\hline LEGEND: BISP = Behavioral Intention to change Service Provider; N = Sample Size \\
\hline
\end{tabular}


Table 4. Factor Analysis: Rotated Component Matrix

\begin{tabular}{|c|c|c|c|c|c|c|c|c|c|}
\hline \multirow[t]{2}{*}{ Items } & \multicolumn{9}{|c|}{ Component } \\
\hline & 1 (UO) & 2 (FCR) & 3 (SQ) & 4 (RA) & $5(\mathrm{SE})$ & $6(\mathrm{HO})$ & $7(\mathrm{PI})$ & $8(\mathrm{~K})$ & $9(\mathrm{SI})$ \\
\hline UO1 & .788 & .094 & .102 & .041 & .070 & .025 & .087 & -.021 & -.069 \\
\hline UO6 & .783 & .116 & .060 & .095 & .086 & .057 & -.016 & .136 & -.051 \\
\hline UO8 & .758 & .106 & .054 & .053 & .035 & .062 & .121 & -.038 & .093 \\
\hline U05 & .740 & .079 & .025 & .041 & .070 & .146 & -.034 & .077 & .118 \\
\hline UO4 & .682 & .121 & .094 & .194 & .027 & .084 & .041 & .153 & .014 \\
\hline UO2 & .679 & .041 & .028 & .107 & .019 & -.071 & .079 & .174 & .168 \\
\hline UO3 & .663 & .124 & .035 & .188 & .261 & .096 & .132 & .028 & -.063 \\
\hline UO10 & .564 & .240 & .179 & .347 & .143 & .100 & .227 & .184 & -.006 \\
\hline UO7 & .520 & -.002 & -.078 & .368 & .169 & -.038 & .134 & .109 & .021 \\
\hline UO9 & .519 & .309 & .139 & .246 & .058 & .021 & .227 & .227 & .096 \\
\hline FCR3 & .171 & .780 & .190 & .079 & .130 & .103 & .024 & .022 & .020 \\
\hline FCR1 & .133 & .768 & .133 & .073 & .228 & -.037 & .084 & .201 & .020 \\
\hline FCR4 & .107 & .687 & .029 & .056 & .238 & -.026 & .067 & .212 & .102 \\
\hline FCR2 & .234 & .649 & .016 & .206 & -.089 & .058 & .042 & -.016 & -.070 \\
\hline SQ4 & .087 & .068 & .858 & .053 & .134 & .017 & .041 & .014 & -.048 \\
\hline SQ1 & .057 & .132 & .794 & .063 & -.083 & .024 & .011 & .024 & .007 \\
\hline SQ3 & .041 & .017 & .769 & .013 & .225 & .068 & .183 & .094 & .032 \\
\hline SQ2 & .111 & .081 & .650 & -.047 & -.027 & .089 & .097 & .038 & .102 \\
\hline RA4 & .137 & .153 & .038 & .728 & .125 & .022 & .001 & -.073 & .105 \\
\hline RA2 & .197 & .124 & .053 & .706 & .129 & .118 & .017 & .308 & .022 \\
\hline RA1 & .222 & .026 & -.039 & .683 & .165 & -.054 & .048 & .256 & .017 \\
\hline RA3 & .373 & .175 & .054 & .589 & .112 & .022 & -.013 & .196 & -.080 \\
\hline SE2 & .120 & .115 & .095 & .117 & .844 & .055 & -.035 & .178 & .003 \\
\hline SE3 & .230 & .188 & .088 & .179 & .795 & .013 & .016 & .262 & .032 \\
\hline SE1 & .172 & .183 & .045 & .241 & .771 & -.005 & .095 & .139 & -.023 \\
\hline HO2 & .048 & .010 & .024 & .135 & .099 & .853 & .111 & -.063 & -.011 \\
\hline HO3 & .081 & .030 & .109 & -.151 & -.049 & .793 & .133 & .099 & .135 \\
\hline HO1 & .226 & .090 & .038 & .116 & .148 & .767 & .187 & -.057 & .047 \\
\hline HO4 & -.028 & -.013 & .060 & -.015 & -.138 & .600 & -.055 & .208 & .268 \\
\hline PI1 & .092 & -.010 & .093 & .036 & .005 & .132 & .897 & .063 & .108 \\
\hline PI2 & .123 & .067 & .065 & -.017 & .058 & .163 & .864 & .015 & .117 \\
\hline PI3 & .298 & .216 & .271 & .077 & -.008 & .064 & .654 & .033 & .036 \\
\hline K3 & .215 & .123 & .115 & .255 & .192 & .054 & .011 & .758 & -.021 \\
\hline K2 & .182 & .064 & .067 & .163 & .311 & .020 & -.025 & .754 & -.010 \\
\hline K1 & .173 & .314 & .015 & .147 & .130 & .108 & .177 & .615 & .033 \\
\hline SI1 & .065 & .034 & .034 & .112 & .011 & .143 & .160 & -.049 & .910 \\
\hline SI2 & .108 & .026 & .061 & -.021 & .005 & .193 & .091 & .039 & .903 \\
\hline
\end{tabular}

Extraction Method: principal component analysis.

Rotation Method: Varimax with Kaiser normalization. 
reliability and the remaining five illustrate high reliability. High Cronbach's $\alpha$ values for all constructs imply that the measures are internally consistent. This in turn suggests that all items of each of the constructs are measuring the same content universe (i.e., construct).

\subsection{Construct Validity Using Factor Analysis}

In order to verify the construct validity (convergent and discriminant validity), a factor analysis was conducted utilizing principal component analysis (PCA) with Varimax as an extraction method, and Kaiser normalization as a rotation method. The results of the PCA are presented in Table 4. All constructs had Eigenvalues greater than one and in combination accounted for a total of 67.13 percent variance in data. The rotated component matrix presented in Table 4 shows the factor loadings for all nine independent constructs, which clearly suggest that the nine components are loaded. All items loaded above 0.40 , which is the minimum recommended value in IS research (Straub et al. 2004). Also, cross loading of the items was not found above 0.40. The aforementioned description suggests that the items were properly loaded on each factor, as was expected. The factor analysis results satisfied the criteria of construct validity including both the discriminant validity (loading of at least 0.40 , no cross-loading of items above 0.40) and convergent validity (Eigenvalues of 1, loading of at least 0.40 , items that load on posited constructs) (Straub et al. 2004, p. 410). This confirms construct validity (both discriminant validity and convergent validity) in the instrument measures utilized for data collection in this research. This suggests that the data collected and findings obtained from this instrument are reliable.

\subsection{Regression Analysis}

A regression analysis was performed with behavioral intention $(B I)$ as the dependent variable and relative advantage (RA), utilitarian outcomes $(U O)$, hedonic outcomes $(H O)$, primary influence (PI), facilitating conditions resources $(F C R)$, knowledge $(K)$, and self-efficacy $(S E)$ as the predictor variables. A total of 358 cases were analyzed. From the analysis, a significant model emerged $(F(7,358)=40.576, p<0.001)$ with the adjusted $\mathrm{R}$ square being 0.437 . Significant variables include $F C R(\beta=.169, p<$ $.001), H O(\beta=.094, p=.027), P I(\beta=.196, p<.001), S E(\beta=.139, p=.005)$, and $R A$ $(\beta=.230, p<.001) . K(\beta=.086, p=.121)$ and $U O(\beta=.098, p=.072)$ were not considered to be significant predictors in this model. The $p$ value of the $U O$ construct was close to the significance level but for the $K$ construct it was not. Therefore, it was decided to undertake another regression analysis cycle, keeping the other settings as above but removing the $K$ construct from the predictors list. In the second regression cycle, the number of predictor variables was reduced to six, with knowledge $(K)$ being eliminated from the list. A total of 358 cases were analyzed. From the analysis, a significant model emerged $(F(6,358)=46.749, p<.001)$. The adjusted $\mathrm{R}$ square was 0.435 . This time all six, including the utilitarian outcomes $(U O)$ predictor variables, were found to be significant. These include FCR $(\beta=.169, p<.001), H O(\beta=.100$, $p=.018), P I(\beta=.195, p<.001), S E(\beta=.165, p<.001), R A(\beta=.255, p<.001)$, and $U O(\beta=.113, p=.035)$. 
As illustrated in Table 5, the constructs are arranged according to their size of $\beta$ values in decreasing order. The size of $\beta$ suggests that $R A$ construct has the largest impact in the explanation of variations of $B I$. This is followed by the $P I$ construct and then $F C R$. This suggests that the three constructs that have the largest impact in explaining variance of $B I$ belong to all three categories (i.e., attitudinal, normative, and control constructs).

When performing a regression analysis, an important cause of concern is the existence of multicolinearity amongst independent variables such as $R A, P I, F C R, S E$, $U O$, and $H O$. It is likely to exist when the independent variables included in the analysis are not truly independent and measure redundant information (Myers 1990). SPSS provides two options to estimate the tolerance and variance inflation factor (VIF) to trace if data suffers with the problem of multicolinearity (Brace et al. 2003; Myers 1990). In order to detect multicolinearity in this research, both VIF and tolerance estimated are shown in Table 5. Values obtained for both VIF and tolerance indicate that multicolinearity was not a problem in this work. Table 5 illustrates that the VIF for this model varied between 1.80 for $P I$ constructs and 1.12 for $\mathrm{HO}$ constructs, which is within recommended levels (Brace et al. 2003; Myers 1990; Stevens 1996).

Table 5. Regression Analysis: Coefficients ${ }^{\dagger}$

\begin{tabular}{|c|c|c|c|c|c|c|c|c|}
\hline & \multicolumn{2}{|c|}{$\begin{array}{l}\text { Unstandardize } \\
\text { d Coefficients }\end{array}$} & \multirow{2}{*}{\begin{tabular}{|c|}
$\begin{array}{c}\text { Standardized } \\
\text { Coefficients }\end{array}$ \\
$\beta$ \\
\end{tabular}} & \multirow[b]{2}{*}{$\mathbf{t}$} & \multirow[b]{2}{*}{$\mathbf{p}$} & \multirow[b]{2}{*}{$\begin{array}{c}\text { Partial } \\
\text { Correlations } \\
\end{array}$} & \multicolumn{2}{|c|}{$\begin{array}{c}\text { Colinearity } \\
\text { Statistics }\end{array}$} \\
\hline & B & $\begin{array}{l}\text { Std. } \\
\text { Error }\end{array}$ & & & & & Tolerance & VIF \\
\hline$($ Constant $)$ & -.904 & .432 & & -2.093 & .037 & & & \\
\hline $\mathrm{RA}$ & .384 & .077 & .255 & 4.962 & .000 & .256 & .601 & 1.664 \\
\hline PI & .196 & .045 & .195 & 4.362 & .000 & .227 & .789 & 1.267 \\
\hline FCR & .191 & .049 & .180 & 3.916 & .000 & .205 & .749 & 1.335 \\
\hline SE & .206 & .058 & .165 & 3.582 & .000 & .188 & .742 & 1.347 \\
\hline UO & .153 & .072 & .113 & 2.116 & .035 & .112 & .555 & 1.801 \\
\hline HO & .097 & .041 & .100 & 2.382 & .018 & .126 & .890 & 1.124 \\
\hline
\end{tabular}

\subsection{Logistic Regression Analysis}

A logistic regression analysis was performed with broadband adoption as the dependent variable and $B I$ and $F C R$ as the predictor variables. A total of 358 cases were analyzed and the full model was considered to be significantly reliable $\left(\chi^{2}(2, N=358)=128.559\right.$, $p<.001)$. This model accounted for between 30.2 percent and 40.6 percent of the variance in broadband adoption (Table 6), with 88.4 percent of broadband adopters being successfully predicted. However, only 58.9 percent of predictions for nonadopters were accurate. Overall, 76.0 percent of predictions were accurate.

Table 7 illustrates coefficients, Wald statistics, associated degrees of freedom, and probability values for each of the predictor variables. This reveals that both $B I$ and $F C R$ constructs reliably predicted broadband adoption. Values of the coefficients 
suggest that each unit increases in $B I$ and the $F C R$ score is associated with an increase in the odds of broadband adoption by a factor of 2.50 and 1.58 respectively (Table 7). This means that $B I$ has a larger part in explaining actual adoption than $F C R$.

\subsection{The Relationship between Service Quality (SQ), Secondary Influence (SI) and Behavioral Intention to Change Service Provider (BISP)}

A further regression analysis was conducted with $B I S P$ as the dependent variable and $S I$ and $S Q$ as predictor variables. A total of 308 cases were analyzed. From the analysis, a significant model emerged $(F(2,308)=13.239, p<.001)$, with an adjusted R square of 0.074 . Both predictor variables were found to be significant (Table 8): $S I(\beta=.153 p=.006)$ and $S Q(\beta=-.255, p<.001)$. Thus $S Q$ is negatively correlated with $B I S P$, which indicates that the lower the quality of the service provided, the higher the chance that consumers will change service providers. However, it is important to note that since the adjusted $\mathrm{R}$ square is very low, $S Q$ and $S I$ have limited explanatory prowess in terms of variation in BISP, which in turns indicates the possibility of other constructs that should be reexamined in the context of continued adoption of broadband.

Table 6. Logistic Regression: Model Summary

\begin{tabular}{|c|c|c|}
\hline Step & Cox \& Snell $\mathbf{R}^{\mathbf{2}}$ & ${\text { Nagelkerke } \mathbf{R}^{\mathbf{2}}}$ \\
\hline 1 & .302 & .406 \\
\hline
\end{tabular}

Table 7. Logistic Regression: Variables in the Equation

\begin{tabular}{|l|l|l|l|l|c|l|l|}
\hline \multicolumn{2}{|l|}{} & \multicolumn{1}{|c|}{ B } & \multicolumn{1}{|c|}{ S.E. } & Wald & df & p & $\operatorname{Exp}(\mathbf{B})$ \\
\hline $\begin{array}{l}\text { Step } \\
1^{\dagger}\end{array}$ & BI & .916 & .141 & 42.021 & 1 & .000 & 2.500 \\
\hline & FCR & .455 & .109 & 17.471 & 1 & .000 & 1.576 \\
\hline & Constant & -7.529 & .954 & 62.222 & 1 & .000 & .001 \\
\hline
\end{tabular}

Table 8. Regression Analysis: Coefficients ${ }^{\dagger}$

\begin{tabular}{|c|l|c|c|c|c|c|}
\hline \multirow{2}{*}{ Model } & \multirow{2}{*}{ Predictors } & \multicolumn{2}{|c|}{$\begin{array}{c}\text { Un standardized } \\
\text { Coefficients }\end{array}$} & $\begin{array}{c}\text { Standardized } \\
\text { Coefficients }\end{array}$ & & \\
\cline { 3 - 5 }$n n$ & $\mathrm{~B}$ & Std. Error & $\beta$ & $\boldsymbol{t}$ & $\mathbf{p}$ \\
\hline 1 & (Constant) & 4.495 & .415 & & 10.843 & .000 \\
\hline & SQ & -.359 & .078 & -.255 & -4.619 & .000 \\
\hline & SI & .166 & .060 & .153 & 2.774 & .006 \\
\hline
\end{tabular}

Table 5 suggest that the paths from relative advantage, $U O$ and $H O$ toward the behavioral intention (BI) to adopt broadband are significant. Consistent with the proposed model, the fourth attitudinal construct $(S Q)$ significantly explained the $B I S P$. As was expected, the path from $P I$ to $B I$ is significant. The second normative 
construct ( $S I$ ) is significantly related to $B I S P$. Of the three control constructs, two ( $S E$ and $F C R$ ) are significantly related to $B I$. However, the path from the third control construct $(K)$ to $B I$ is not significant. Finally, both $B I$ and $F C R$ are significant determinants of the actual behavior of adopting broadband.

It is not possible to directly compare the predictability of our broadband adoption model with the study by $\mathrm{Oh}$ et al. (2003) as both studies examined different independent and dependent constructs. For instance, this study employed $B I$ and actual behavior as dependent constructs, but in Oh et al.'s study the dependent construct was attitude. However, the predictive power of our broadband adoption model can be compared to models such as TAM, TPB, and DTPB as the behavior and structure of our broadband adoption model are similar to TAM, TPB, and DTPB. Table 9 illustrates the comparison of previous studies for the adjusted $R^{2}$ obtained for both Behavioral intention and actual behavior. The comparison clearly demonstrates that the broadband adoption model performed well when compared to previous studies.

Table 9 illustrates that the $B I$ value of the adjusted $R^{2}$ varied between 0.20 (Gefen and Straub 2000) and 0.57 (Taylor and Todd 1995), with the adjusted $R^{2}$ for this study being 0.43 , which suggests an appropriate level of explained variance. This suggests that the independent variables considered in this study are important for understanding consumers' Behavioral intention to adopt broadband. In terms of behavior, the adjusted $R^{2}$ reported in previous studies varied between 0.32 (Davis et al. 1989) and 0.51 (Davis 1989). Since the adjusted $R^{2}$ value in this study for variance in behavior was 0.40 , it falls within the range of previous works.

Table 9. Comparison of Intention and Behavior in Terms of Adjusted $\mathrm{R}^{2}$

\begin{tabular}{|l|l|c|c|}
\hline \multirow{2}{*}{ Study } & & \multicolumn{2}{c|}{ Adjusted R2 } \\
\cline { 3 - 4 } & \multicolumn{1}{|c|}{ Theory } & $\begin{array}{c}\text { Behavioral } \\
\text { Intention }\end{array}$ & Behavior \\
\hline Davis et al. (1989) & TAM & - & 0.45 \\
\hline Davis et al. (1989) & TRA & - & 0.32 \\
\hline Davis (1989) & TAM & - & 0.51 \\
\hline Taylor and Todd (1995) & DTP & 0.57 & 0.34 \\
\hline Taylor and Todd (1995) & TPB & 0.52 & 0.34 \\
\hline Taylor and Todd (1995) & TAM & 0.38 & - \\
\hline Karahanna et al. (1999) & TRA + TAM & 0.50 & - \\
\hline Agarwal and Karahanna (2000) & TAM \& Cognitive & & \\
\hline Gefen and Straub (2000) & Absorption & 0.20 & - \\
\hline Brown et al. (2002) & TAM & 0.52 & - \\
\hline Koufaris (2002) & TAM & 0.54 & - \\
\hline This Study & TAM + Flow Theory & $\mathbf{0 . 4 3}$ & $\mathbf{0 . 4 0}$ \\
\hline $\begin{array}{l}\text { Recommended level } \\
\text { (Straub et al. 2004) }\end{array}$ & TPB + DTPB + MATH & $\mathbf{0 . 4 0}$ or & $\mathbf{0 . 4 0}$ or \\
above & above \\
\hline
\end{tabular}




\section{Conclusions and Implications}

A total of seven constructs from attitudinal (relative advantage, utilitarian outcomes, and hedonic outcomes), normative (primary influence) and control (knowledge, selfefficacy, and facilitating conditions resources) categories were expected to influence behavioral intention $(B I)$ of consumers when adopting broadband in the UK household. Our study revealed that all of the aforementioned constructs except knowledge significantly influenced the $B I$ of UK consumers when adopting broadband. In terms of the size of the effect of these significant constructs relative advantage exhibited the largest and hedonic outcomes the least variance of $B I$. Primary influence explained the second largest variance, which was followed by facilitating conditions resources. The fourth strongest construct was self-efficacy, and the fifth was utilitarian outcomes. Both BI and the control construct appear to significantly influence broadband adoption behavior in UK households. In terms of the relative impact of the two aforementioned constructs that contributed significantly to the broadband adoption behavior $(B A B)$, BI had much higher impacts than the control construct.

\subsection{Contributions to Theory}

The first contribution of this research toward theory is that it integrates the appropriate IS literature in order to enhance the knowledge of IT/IS adoption from the consumer perspective. That is, it assimilates previous research findings to develop a coherent and comprehensive picture of the technology adoption research conducted in the IS field. By doing so, this work introduces a conceptual model of broadband adoption that integrates factors from different technology adoption models with the objective of studying technology diffusion in the home environment from a consumer's perspective. The second contribution is to empirically confirm the appropriateness of various constructs and validate the conceptual model in the context of household consumers. Considering the above points, this study has made distinct contributions to the area of technology adoption and diffusion in general and broadband adoption in particular.

\subsection{Implications for the Industry and Policy}

It was found that relative advantage was most important and hedonic outcomes least important in terms of influencing behavioral intention when adopting broadband in UK households. Other important constructs that fall within these two extremes were primary influence, facilitating conditions resources, self-efficacy, and utilitarian outcomes. The findings of this research raise a number of issues that may assist both policy makers and ISPs for understanding consumer adoption of broadband. For example, since relative advantage is found to be the most influential construct, it indicates that ISPs have to provide broadband services to consumers by offering a package that demonstrates clear advantage over narrowband facilities or existing broadband arrangements. Facilitating conditions resources is the third most important factor in terms of influencing $B I$ to adopt broadband. This has implications for both ISPs and policy makers as, for instance, ISPs need to think about more consumer-centric services and alternative price plans so 
that all consumers who want to subscribe to broadband are able to do so. Policy makers have to provide alternative places for broadband access where lower income groups or those who cannot afford it can use it, as this may help increase Behavioral intention to adopt broadband and therefore encourage overall adoption and diffusion of broadband. As mentioned above, self-efficacy is also an important influencing factor which touches upon policy-related issues, suggesting that there is a need to equip citizens with the skills required to use computers and the Internet. Since both utilitarian outcomes and hedonic outcomes are important factors for explaining Behavioral intentions, it is important to provide more content and applications for the purpose of household utility and entertainment.

\subsection{Research Limitations and Future Research Directions}

This study provides a snapshot of adoption of broadband in UK households. The findings may change as the technology becomes established, and as consumers become more experienced in its use. The findings would also have been reinforced had the research been longitudinal. Our study employed a quantitative approach, and we acknowledge that this may have limited the ability to obtain an in-depth view of household technology adoption. The questionnaire findings would have been strengthened had they been supplemented by interview data; however, time and resource restrictions dictated that it was not possible to conduct both qualitative and quantitative investigations. With regard to broadband adoption in the future, we intend to examine whether the findings from this study are specific to UK consumers or whether the results will be transportable to other countries, particularly in developing nations where broadband adoption is still at an embryonic stage.

\section{References}

Agarwal, R., Karahanna, E.: Time Flies When You're Having Fun: Cognitive Absorption and Beliefs about Information Technology Usage. MIS Quarterly 24(4), 665-694 (2000)

Ajzen, I.: The Theory of Planned Behavior. Organizational Behavior and Human Decision Processes 50, 179-211 (1991)

Brace, N., Kemp, R., Snelgar, R.: SPSS for Psychologists: A Guide to Data Analysis Using SPSS for Windows. Palgrave Macmillan, New York (2003)

Brown, S.A., Massey, A.P., Montoya-Weiss, M.M., Burkman, J.R.: Do I Really Have To? User Acceptance of Mandated Technology. European Journal of Information Systems 11(4), 267$282(2002)$

BSG Briefing Paper. The Impact of Broadband-Enabled ICT, Content, Applications and Services on the UK Economy and Society to 2010, London (2004),

http: / / www. broadbanduk.org/news / news_pdfs / Sept\%2 02004 /

BSG_Phase_2_BB_Impact_BackgroundPaper_Sept 041 .pdf (accessed

October 30, 2004)

Choudrie, J., Dwivedi, Y.K.: The Demographics of Broadband Residential Consumers of a British Local Community: The London Borough of Hillingdon. Journal of Computer Information Systems 45(4), 93-101 (2005)

Choudrie, J., Dwivedi, Y.K.: Investigating Factors Influencing Adoption of Broadband in the Household. Journal of Computer Information Systems 46(4), 25-34 (2006) 
Choudrie, J., Dwivedi, Y.K.: Broadband Impact on Household Consumers: Online Habits and Time Allocation Patterns on Daily Life Activities. International Journal of Mobile Communications 5(2), 225-241 (2007)

Crabtree, J.: Fat Pipes, Connected People-Rethinking Broadband Britain. iSOCIETY Report, London (2003), http: / / www . theworkfoundation. com/pdf / 1843730146.pdf (accessed March 30, 2004)

Davis, F.D.: Perceived Usefulness, Perceived Ease of Use, and User Acceptance of Information Technology. MIS Quarterly 13(3), 319-340 (1989)

Davis, F.D., Bagozzi, R.P., Warshaw, P.R.: User Acceptance of Computer Technology: A Comparison of Two Theoretical Models. Management Science 35(8), 982-1003 (1989)

Dwivedi, Y.K., Irani, Z.: Understanding the Adopters and Non-adopters of Broadband. Communications of the ACM 52(1), 122-125 (2009)

Dwivedi, Y.K., Choudrie, J., Brinkman, W.P.: Consumer Usage of Broadband in British Households. International Journal of Services and Standards 2(4), 400-416 (2006a)

Dwivedi, Y.K., Choudrie, J., Brinkman, W.P.: Development of a Survey Instrument to Examine Consumer Adoption of Broadband. Industrial Management and Data Systems 106(5), 700-718 (2006b)

Fowler Jr., F.J.: Survey Research Methods. SAGE Publications Inc., London (2002)

Gefen, D., Straub, D.W.: The Relative Importance of Perceived Ease of Use in IS Adoption: A Study of E-Commerce Adoption. Journal of the Association for Information Systems (1), 1-28 (2000)

Hinton, P.R., Brownlow, C., McMurray, I., Cozens, B.: SPSS Explained. Routledge Inc., East Sussex (2004)

Irani, Z., Dwivedi, Y.K., Williams, M.D.: Understanding Consumer Adoption of Broadband: An Extension of Technology Acceptance Model. Journal of Operational Research Society 60(10), 1322-1334 (2009)

Karahanna, E., Straub, D.W., Chervany, N.L.: Information Technology Adoption Across Time: A Cross-Sectional Comparison of Pre-Adoption and Post-Adoption Beliefs. MIS Quarterly 23(2), 183-213 (1999)

Koufaris, M.: Applying the Technology Acceptance Model and Flow Theory to Online Consumer Behavior. Information Systems Research 13(2), 205-223 (2002)

Langdale, J.V.: International Competitiveness in East Asia: Broadband Telecommunications and Interactive Multimedia. Telecommunications Policy 21, 235-249 (1997)

Lee, H., O'Keefe, B., Yun, K.: The Growth of Broadband and Electronic Commerce in South Korea: Contributing Factors. The Information Society 19, 81-93 (2003)

Myers, R.H.: Classical and Modern Regression with Applications. PWS-KENT Publishing Company, Boston (1990)

National Broadband Task Force, The New National Dream: Networking the Nation for Broadband Access, Ottawa Industry, Canada (2001)

OECD. Working Party on Telecommunication and Information Services Policies: The Development of Broadband Access in OECD Countries, OECD, Paris (2001), http: / /www. oecd.org/dataoecd/48/33/2475737.pdf (accessed March 12, 2003)

Office of the e-Envoy. UK Online: The Broadband Future (2001), http://archive. cabinetoffice.gov.uk/e-envoy/reports-broadband/\$file/ ukonline.pdf (accessed July 15, 2003)

Office of Technology Policy. Understanding Broadband Demand: A Review of Critical Issues, U.S. Department of Commerce, Washington, DC (2002) 
Oh, S., Ahn, J., Kim, B.: Adoption of Broadband Internet in Korea: The Role of Experience in Building Attitude. Journal of Information Technology 18(4), 267-280 (2003)

Rice, C.: Understanding Customers. Butterworth-Heinemann, Oxford (1997)

Rogers, E.M.: Diffusion of Innovations. Free Press, New York (1995)

Sawyer, S., Allen, J.P., Heejin, L.: Broadband and Mobile Opportunities: A Socio-Technical

Perspective. Journal of Information Technology 18(4), 121-136 (2003)

Stanton, L.J.: Factors Influencing the Adoption of Residential Broadband Connections to

Internet. In: Proceedings of the 37th Hawaii International Conference on System Sciences.

IEEE Computer Society Press, Los Alamitos (2004)

Stevens, J.: Applied Multivariate Statistics for the Social Sciences. Lawrence Erlbaum Associates, Inc., Mahwah (1996)

Straub, D.W., Boudreau, M.-C., Gefen, D.: Validation Guidelines for IS Positivist Research.

Communications of the Association for Information Systems 13, 380-427 (2004)

Suomi, R., Pekkola, J.: Inhibitors and Motivators for Tele-work: Some Finnish Experiences.

European Journal of Information Systems 7(4), 221-231 (1998)

Taylor, S., Todd, P.A.: Understanding Information Technology Usage: A Test of Competing Models. Information Systems Research 6(1), 44-176 (1995)

Venkatesh, V., Brown, S.: A Longitudinal Investigation of Personal Computers in Homes: Adoption Determinants and Emerging Challenges. MIS Quarterly 25(1), 71-102 (2001)

\section{About the Authors}

Yogesh K. Dwivedi is a senior lecturer in Information Systems at the School of Business and Economics, Swansea University, UK. His research focuses on the adoption and diffusion of ICT in organizations and society. He has coauthored several papers which have appeared in international referred journals such as Communications of the ACM, DATA BASE, European Journal of Information Systems, Information Systems Journal, Information Systems Frontiers, Journal of Computer Information Systems, Journal of Information Technology, Journal of the Operational Research Society, and Industrial Management \& Data Systems. He has authored, coauthored, or coedited eight books on a variety of IS topics. He is senior editor of DATA BASE, assistant editor of Transforming Government: People, Process and Policy, and managing editor of Journal of Electronic Commerce Research. He is a member of the Association for Information Systems, IFIP WG8.6, and the Global Institute of Flexible Systems Management, New Delhi. He can be reached at ykdwivedi@gmail.com.

Navonil Mustafee is a lecturer in Information Systems at the School of Business and Economics, Swansea University, UK. Previously he worked as a research fellow in Grid Computing and Simulation in the School of Information Systems, Computing and Mathematics, Brunel University (UK). He received his M.Sc. in Distributed Information Systems and Ph.D. in Information Systems and Computing from Brunel University (UK). His research interests are in grid computing, parallel and distributed simulation, and healthcare simulation and information systems. His e-mail address is Navonil.Mustafee@gmail.com

Michael D. Williams is a arofessor in the School of Business and Economics at Swansea University in the UK. He holds a BSc from the CNAA, an M.Ed. from the University of Cambridge, and a Ph.D. from the University of Sheffield. He is a 
member of the British Computer Society and is registered as a Chartered Engineer. Prior to entering academia Professor Williams spent 12 years developing and implementing ICT systems in both public and private sectors in a variety of domains including finance, telecommunications, manufacturing, and local government, and since entering academia, has acted as consultant for both public and private organizations. He is the author of numerous fully refereed and invited papers within the ICT domain, has editorial board membership with a number of academic journals, and has obtained external research funding from sources including the European Union, the Nuffield Foundation, and the Welsh Assembly Government. He can be reached at m.d.williams@swansea.ac.uk

Banita Lal is a lecturer in the Nottingham Business School, Nottingham Trent University, UK. She obtained her Ph.D. and M.Sc. in Information Systems from Brunel University. Her research interests involve examining the individual and organizational adoption and usage of ICTs and technology-enabled alternative forms of working. She has published several research papers in internationally refereed journals such as Journal of Information Technology, Industrial Management \& Data Systems, Information Systems Frontiers, Electronic Government, International Journal of Mathematics and Computation, and Transforming Government: People, Process and Policy, and has presented several papers at several international conferences. She can be reached at banita.lal@ntu.ac.uk 